\title{
Chicanos y mexicoamericanos en tres comunidades electrónicas
}

\author{
Francisco JaVier Cortázar RodríGuez** \\ fcovier@yahoo.com
}

\begin{abstract}
Este trabajo se centra en los mensajes producidos en tres grupos de discusión electrónicos (newsgroups) chicanos y mexicoamericanos en Internet con temas de literatura, arte y sociedad de la comunidad chicana de Estados Unidos. El trabajo se basa en más de 800 mensajes impresos entre mediados de junio y mediados de septiembre de 2001. El propósito del artículo es estudiar las formas en que se expresan las identidades colectivas a través de medios electrónicos.
\end{abstract}

This paper focuses on the 800 Internet's messages of literature, art, and society that were produced by three Chicanos and Mexican-American's newsgroups between June and September 2001. The main purpose of this article is to study the forms of expression into collective identities through Internet.

\section{INTRODUCCIÓN}

El trabajo que el lector tiene entre en sus manos forma parte de una investigación más amplia sobre las comunidades electrónicas en Internet, que comprende de mediados de 2001 a finales de 2002. Este artículo se concentra en el periodo comprendido de junio a septiembre de 2001, en el que se han impreso más de 800 mensajes electrónicos provenientes de los tres grupos bajo estudio.

Las preguntas que se plantean están relacionadas con los impactos reales que la comunicación electrónica tiene entre los grupos minoritarios de ascendencia mexicana en Estados Unidos a

*Universidad de Guadalajara. 
través de Internet, sobre cómo y por quiénes es discutida su identidad cultural y étnica, sus formas de actuar, su memoria colectiva, sus temas de debate y formas de producir acuerdos y desacuerdos. Estas preguntas se enmarcan en las discusiones sobre la llamada "sociedad de la información", la "revolución de Internet" y las "comunidades virtuales". Ante la multiplicidad de textos triunfalistas y prospectivos sobre los anteriores términos, en este trabajo se plantea una investigación de carácter empírico, con estudios de caso, en periodos cronológicos bien delimitados y que permitan las comparaciones entre grupos sociales semejantes.

Contrariamente a buena parte de la literatura sobre el tema (Quéau 1995; Negroponte 1996; Rushkoff 2000; Dyson 2000) considero que Internet y la comunicación electrónica no son una revolución que cambiarán las relaciones sociales entre las personas haciéndolas "más transparentes", ni eliminarán a los Estados, ni se formarán "comunidades" donde los individuos se expresarán libremente en la plaza pública y se harán oír en todo el planeta, donde las computadoras y las redes serán la base de "inteligencias colectivas". Antes bien, me identifico con las tesis que inscriben a la tecnología y sus discursos en ámbitos precisos de la historia, la política y la sociedad (Dery 1997; Wolton 1999; Breton 2000; Flichy 2001; Mattelart 2001; Dupuy 2002). Pretender que el mundo puede cambiar gracias a Internet, hacerlo más armonioso, implicaría perder de vista los conflictos y los intereses, negar las divisiones, olvidar las posiciones y los juegos de poder y renunciar a la crítica.

Con el discurso empleado por los más fervientes partidarios del "todo Internet" se nos quiere hacer creer que el "ciberespacio" carece de fronteras pues sus alcances son ilimitados. Es decir, se trataría de una "nueva frontera" que hay que conquistar y colonizar, a la manera del viejo oeste norteamericano. Creer en este discurso implica olvidar la pluralidad de actores presentes en el desarrollo de Internet: operadores de telecomunicaciones presentes en mercados con consumidores y productos; donde la información sigue caminos e itinerarios, orígenes y destinos; que la Red 
tiene puntos fuertes y débiles; donde hay centros y periferias; donde las fronteras no han sido abolidas, en particular las fronteras entre los Estados (hay Estados que controlan celosamente el acceso y la utilización de Internet), las fronteras linguiísticas, las fronteras culturales y las fronteras tecnológicas.

Tampoco me adhiero a una idea apocalíptica o antitecnológica. No se trata de estar "contra" o "por" Internet. Ése es un falso debate. El futuro de Internet no será ni armonioso ni apocalíptico, pues aparecerán nuevos actores, diferentes lógicas, otras tecnologías y nuevas regulaciones.

\section{ESTADOS UNIDOS, INTERNET Y LA ETNIA}

A finales de enero de 2003 la oficina censal de Estados Unidos anunció que la población latina de ese país pasaba a ser la primera minoría étnica, por delante de la población negra. A diferencia de otros grupos étnicos, los latinos han sido en general renuentes a integrarse en el llamado melting pot (crisol) y en el mainstream cultural (corriente principal, forma de pensar mayoritaria) estadunidense. El subgrupo étnico formado por mexicanos que han migrado y estadunidenses de origen mexicano, es el más numeroso entre los latinos: más de 22 millones (de un total de 37 millones de hispanos/latinos). ${ }^{1}$ Por su importancia creciente como consumidores (mercados) y peso político (votos), los hispanos son objeto de una atención creciente.

Los hispanos de origen mexicano se hacen llamar de formas diferentes según se trate de generaciones, lugar de residencia, niveles socioeconómicos y culturales y situación coyuntural. Mientras unos se hacen llamar chicanos, otros prefieren llamarse a sí mismos americanos de origen mexicano, mexican-americans (con guión), mexicanamericans (sin guión), hispanos, latinos, ameri-

${ }^{1}$ Véase al respecto "Un fenómeno social, pero también político. Latinos en Estados Unidos: un público, un mercado, muchos votos", Clarín.com, 26 de enero de 2003 (www.clarin.com) y "Mexican-Origin Population in California: Health Fact Sheet”. Berkeley: University of California. (www.ucop.edu/cprc/ cmhi.html). 
canos con raíces latinas, latinoamericanos, etc. Ante esta heterogeneidad, he optado en el título de este trabajo por llamarles de las dos formas predominantes entre este grupo étnico: chicanos y mexicoamericanos. Ambos términos parecen ser sinónimos pero en realidad son, por sus contenidos identitarios y simbólicos, muy diferentes. ${ }^{2}$ Por otra parte, para facilitar la lectura de estas líneas emplearé un solo término: chicanos.

Una característica de los hispanos en Estados Unidos es que son el único grupo étnico que cuenta con una amplia gama de medios de comunicación hablados en su idioma, el español. García Canclini (1999: 138) cita los datos del Directorio Nacional de Medios Hispanos correspondiente a 1998, según el cual existían en ese año en Estados Unidos 1,214 publicaciones periódicas en español (entre ellas 24 diarias y 246 semanales), 93 televisoras (la mayoría agrupadas en dos grandes redes: Telemundo y Univisión), 591 estaciones de radio y 340 "servicios" de Internet.

Ahora bien, siendo Estados Unidos el país donde nació y se desarrolló Internet, donde su tasa de utilización es muy elevada, que es el país donde se crean y se ponen en circulación buena parte de los contenidos disponibles en Internet, cuya hegemonía linguiística se deja sentir mundialmente y por ser el país que más ha moldeado el discurso que acompaña el desarrollo de la Red, nos preguntamos: ¿de qué forma Internet permite el contacto entre minorías geográficamente dispersas con intereses comunes y por medio de qué herramientas informáticas? ¿Dé que forma los chicanos discuten su identidad y recrean su herencia sociocultural a través de circuitos alternativos a los medios de masas en una sociedad como la estadunidense? ¿De qué manera los nuevos medios electrónicos contribuyen a la visibilidad de grupos mino-

${ }^{2}$ Chicano es un término empleado principalmente en California; surgió en la década de los sesenta con el Movimiento Chicano, es de carácter militante y aboga por una fuerte identificación con un pasado mítico (Aztlán) y posee fuertes raíces con la cultura popular mexicana, mientras que mexicoamericano es un término empleado como "alternativa" al primero, tiene un carácter más asimilacionista a la cultura norteamericana, es de carácter conservador y apolítico y es usado sobre todo en Texas. 
ritarios y a su especialización profesional? ¿Se expresan de formas diferentes los diversos grupos chicanos presentes en Internet? $¿$ Tienen preocupaciones comunes en cuanto a su identidad o su herencia cultural? En las líneas que siguen intento responder a algunas de estas preguntas. Deseo mostrar cómo Internet es usado, influenciado, utilizado, por los grupos sociales presentes en la red de redes y cómo éstos le imponen sus lógicas. Al centrarme en los chicanos y mexicoamericanos deseo ver cómo un grupo étnico-cultural se integra de forma alternativa en una sociedad hegemónica como la estadunidense recuperando y poniendo en escena, haciendo visible, su herencia cultural, sus preocupaciones sociales y políticas, marca "fronteras" con otros grupos étnicos y sociales y se preocupa por lo que sucede en América Latina. No estudio la gran variedad de newsgroups chicanos existentes en Internet, sólo me dedico a tres de ellos que son representativos de un subgrupo: universitarios, investigadores y artistas, es decir, los representantes intelectuales de la cultura chicana al norte del Río Bravo.

\section{Metodología}

En un primer trabajo de recolección de información realizado en Internet encontré no menos de 60 grupos de discusión chicanos de todo tipo. Esta primera búsqueda consistió en un "peinado", mediante palabras clave, del motor de búsqueda Google y del portal Yahoo. Visitando páginas Web chicanas, remitiéndome a ligas y leyendo los menús de newsgoups en Usenet, fui recopilando la información. Por ejemplo, en el servicio Yahoo Groups hay un menú con más de 50 grupos de discusión electrónicos chicanos, entre ellos: aztlanunderground, chicanoconection, aztlannet-earth, aztlan-arte, chicanawriter, purechicanomexican, thechicanoclub, chicanohistory, etcétera. Este menú está organizado de forma descendente, ocupando los primeros puestos los grupos con más suscriptores y al final aquellos con menos; muchos de estos grupos registran niveles de participación nulo o escaso, otros son 
muy activos. Algunos cuentan con varios años de actividad, otros son muy recientes. Al igual que los diversos grupos sociales, algunos grupos de discusión electrónicos conocen periodos de reflujo o decadencia, y otros están en plena efervescencia.

Ante esta diversidad y número decidí adoptar un enfoque comparativo entre tres grupos de discusión electrónicos en dos momentos diferentes. Para lograr la comparación se requerían grupos relativamente homogéneos en temáticas y características de sus integrantes. He optado por tres grupos: Chicle List, Aztlan Net y soc.culture.mexican-american ${ }^{3}$ (por comodidad, a este último lo denominaremos en adelante mexican-american). Estos tres grupos están integrados en su mayoría por hombres y mujeres con educación universitaria, por profesores de departamentos de investigación de universidades estadunidenses, editores, activistas políticos, feministas, escritores, artistas y de otras actividades culturales. Los temas giran en torno a la identidad chicana, su cultura y su historia, las relaciones con otros grupos étnicos, la cultura mexicana, los problemas sociales de América latina, etcétera. Es decir, se trata de grupos de discusión que facilitan la socialización y la discusión colectiva de problemas que preocupan a algunos de los miembros más intelectualizados de la comunidad chicana.

La delimitación temporal está establecida a partir del criterio comparativo: se ha seleccionado el mismo corte de tiempo para los tres foros de discusión, divididos en dos periodos diferentes. El primero comprende tres meses de participación y recolección de información, de mediados de junio a mediados de septiembre de 2001; el segundo consta de seis meses, de junio a noviembre de 2002. Como ya ha sido señalado, este trabajo sólo presenta los resultados de junio a septiembre de 2001. Este primer recorte temporal no ha sido arbitrario, las decisiones que lo justifican son las siguientes.

${ }^{3}$ Las direcciones electrónicas de cada uno de los grupos son: maillist.unm.edu/ cgi-bin/wa?suBED $1=$ chicle $\& A=1$, www.aztlannet.com/aztlannet.html y soc.culture.mexican.american. 
Dos razones coyunturales que se presentaron de forma simultánea me llevaron a interrumpir momentáneamente el trabajo. Esto permitió una primera evaluación de la información disponible, procedimientos de trabajo e hipótesis. La primera razón tiene que ver con el fin del grupo de discusión Clicle List, que dejó de funcionar el 18 de septiembre de 2001, después de 10 años de discusiones ${ }^{4}$ (para la segunda parte de nuestro trabajo de investigación hemos sustituido a este grupo por Chicana Writer, para mantener el criterio de tres grupos diferentes). La segunda razón estriba en los acontecimientos del 11 de septiembre de 2001 en Estados Unidos. Por ser en su gran mayoría ciudadanos estadunidenses, los chicanos se vieron profundamente afectados por los acontecimientos. Los sucesos de esos días modificaron de manera profunda las dinámicas internas de cada grupo, al menos en forma temporal. No excluyo para otra ocasión el análisis de las conversaciones en torno a esos eventos; por el momento las he dejado de lado.

\section{NEWSGROUPS Y SOCIEDAD}

Los grupos de discusión nacieron en 1978 gracias al protocolo informático llamado UUCP (Unix to Unix Copy Program), desarrollado por los estudiantes de informática de las universidades de Duke y Carolina del Norte (Flichy 2001: 65). Al año siguiente fue establecida la red que unió a ambas universidades, llamada Usenet, como abreviación de Usenix Network (Usenix es el término empleado por los usuarios de Unix). En ese tiempo Usenet era una red independiente de Arpanet, antecedente de Internet. Mientras que en Arpanet se usaban las newsletters para comunicar informaciones a varias personas a la vez, en Usenet se usaban los newsgroups. Los newsgroups son programas informáticos que

\footnotetext{
${ }^{4}$ Chile List estaba animado por Teresa Márquez, de la Universidad de Nuevo México. Las razones que llevaron a la animadora a tomar la decisión de cerrar el foro, y según explicó ella misma en un mensaje dirigido a la comunidad "chiclera", fueron los largos años dedicados al grupo y otras necesidades profesionales en su trabajo.
} 
reexpiden a todos los miembros inscritos en el grupo los mensajes enviados por cada persona. Se trata de un sistema inspirado en los tableros de anuncios.

Internet, como medio de comunicación, cuenta con diversas herramientas informáticas, cada una de ellas con ciertas posibilidades y diferentes usos. En nuestro trabajo dividiremos estas herramientas en sincrónicas y asincrónicas (Beaudoin y Velkovska 1999). Los medios electrónicos sincrónicos son aquellos que requieren de la presencia simultánea de los usuarios para comunicarse, como los salones de conversación (chat rooms), las páginas personales, los juegos en línea y la mensajería instantánea (Messenger o ICQ). En cambio los medios electrónicos asincrónicos no requieren de la presencia simultánea de los participantes para comunicarse entre sí. Ejemplos de medios asincrónicos en Internet son el correo electrónico, las listas de difusión (newsletters), los grupos de discusión (newsgroups) y ciertas páginas Web. Los grupos de discusión electrónicos, al no requerir la presencia simultánea de los participantes, permiten a los usuarios responder a mensajes dejados días atrás por otros. A diferencia del correo electrónico, que comunica a dos personas de punto a punto, los grupos de discusión nacieron con la idea de contar con una herramienta informática adaptada a la comunicación colectiva basada en la cooperación de los participantes y en el intercambio de conocimientos. El éxito de un grupo de discusión depende de la participación de cada miembro, de forma que cuando alguien responde a un mensaje dejado por otra persona, se responde más al grupo que a esa persona (Wellman y Gulia 1999). Los grupos de discusión no sólo hacen uso del correo electrónico para dejar mensajes al resto del grupo, sino que emplean varias herramientas, tanto sincrónicas como asincrónicas: mensajes adjuntos (attachment), ligas a otros sitios, uso de chats, imágenes. Sin embargo es la palabra escrita lo que predomina.

Los grupos de discusión electrónicos son lugares de intercambio colectivo, abiertos a todos los interesados con preocupaciones comunes. Al estudiar las llamadas "comunidades electrónicas" debemos prestar una gran atención a sus integrantes, a las dinámicas 
de cada comunidad y a los dispositivos técnicos de comunicación a su alcance (correo electrónico, foros y listas de discusión, paginas Web, etcétera.). En efecto, las exigencias socioprofesionales, los temas de interés discutidos y el uso de herramientas de comunicación electrónicas facilitan la organización de grupos sociales en torno a temas específicos, la socialización y circulación de conocimientos entre sus miembros y la formación de tribus electrónicas de pertenencia, por lo que los aspectos socioculturales de cada grupo predominarán sobre los aspectos tecnológicos. Empleo el término tribus electrónicas en un sentido más amplio que el usado inicialmente por Michel Maffesoli (2000), es decir, como la creación de redes sociales de intercambio y sociabilidad entre personas con intereses comunes a través del uso de tecnologías electrónicas de comunicación, entre las que destaca el uso de Internet.

El análisis detallado de los mensajes intercambiados en los foros de discusión chicanos permite dar cuenta de la vida cotidiana de esos "barrios virtuales" intelectuales, su comunicación con otros grupos, su evolución y decadencia. También permite observar los diferentes niveles de lenguaje empleados por sus miembros, sus discusiones, temas de debate y las representaciones que se hacen de sí mismos como parte de la comunidad chicana en general. Los grupos de discusión funcionan bajo diversos registros asociando elementos culturales, de información y formación institucional, creando solidaridades con otros grupos, desarrollando lenguajes particulares, intercambiando y discutiendo temas de interés común, tomando posiciones, dando sentido a su vida en la pantalla como extensión de la misma fuera de la pantalla, es decir, a los diferentes registros de su identidad como chicanos y como intelectuales.

La investigación social acerca de Internet, como área de estudio, es un oficio que debe hacer público lo que sucede en un espacio público. Internet es un espacio de este tipo, su investigación es similar al estudio de los graffiti murales, los epitafios de las tumbas funerarias o de las cartas a un editor. Sin embargo, es 
necesario diferenciar entre lo público, lo privado y lo personal. Internet es un espacio público, como una plaza, en la que hay encuentros personales. Podemos ser testigos de estos encuentros pero, sin el permiso de los participantes, nos está prohibido grabar las conversaciones que entre ellos ocurren.

Las conversaciones son públicas en los salones de conversación (chat rooms), al igual que los mensajes dejados en los grupos de discusión y listas de difusión. Se trata de mensajes que son expuestos en lugares públicos para consumo público. Esto no significa que podamos emplearlos sin ninguna restricción, por lo que debemos tomar las mismas precauciones que adoptamos en el estudio de la vida cotidiana normal (Cavanagh 1999; Paccagnella 1997; Poster 1996). En cambio, privado es el correo electrónico que se escriben dos personas, y para reproducirlo necesitamos de su permiso.

La etnografía o trabajo de campo, en Internet se realiza mediante la observación, el registro y la participación activa y constante de lo que ahí ocurre. El investigador acompaña virtualmente a los actores sociales en sus actividades a través de Internet y los observa en situación. Es decir, se estudian los trazos visibles y obras que los actores realizan y dejan en la Red: mensajes, páginas personales, conversaciones en línea, pseudónimos, comportamientos, etcétera. Con estos datos podemos interpretar el comportamiento, las ideas, los códigos, las representaciones y la memoria colectiva de los grupos sociales presentes en Internet.

Consideramos a Internet como extensión tanto del mundo real de los sujetos como de los medios de comunicación tradicionales. Es un medio de comunicación y de información. Privilegiamos el primer aspecto, pues deseamos resaltar los usos y fines que los internautas le confieren.

La etnografía en Internet no nos interesa sólo como producto (como productora de trabajos escritos, visuales o de otro tipo), sino también como proceso explicativo. La meta es hacer comprensibles los procesos socioculturales que permiten la apropiación de las nuevas tecnologías por parte de los usuarios y las 
maneras como se sirven de ella para crear nuevas relaciones sociales, organizarse a través de las distancias geográficas, debatir temas de su interés y cuestionarse acerca de su identidad, su memoria colectiva y su futuro.

Privilegiar aspectos como identidad, acción y compromiso en el estudio de Internet permite la comprensión del ciberespacio como un aspecto más de la vida cotidiana de los individuos y de las comunidades electrónicas de pertenencia. Su análisis permite comprender cómo las actividades asociadas a Internet son parte de las actividades cotidianas de los individuos que se estructuran en términos percibidos por ellos mismos a partir de su intersubjetividad (Webb 1999).

Una última cuestión que resta se refiere al aspecto ético de la preservación del anonimato de los miembros en los grupos de discusión y de los mensajes que ahí dejan. En esos grupos cada mensaje escrito es obra de personas singulares, por lo que debemos respetar su intimidad y anonimato. Tanto en los correos electrónicos recopilados como en los archivos electrónicos consultados, aparecen datos personales (nombre y apellidos, dirección de correo electrónico, etc.) y muchos mensajes suelen estar firmados. En los ejemplos seleccionados para este trabajo he optado por eliminar dichos datos, conservando sólo las iniciales del autor, el grupo de discusión de donde proviene la información y la fecha a que corresponde. De igual manera, he conservado la ortografía y la sintaxis originales. Las palabras y expresiones que aparecen originalmente en español han sido resaltadas en cursivas.

Como ya ha sido señalado, el periodo que cubre este trabajo corresponde a tres meses de investigación, de junio a septiembre de $2001 .{ }^{5}$ Este periodo no pretende ser totalmente representativo de la vida de una comunidad electrónica. Se trata sólo de realizar un primer balance de mi participación en la vida de dichas comunidades. Para avanzar de forma pertinente en el trabajo en curso

${ }^{5}$ El grupo mexican.american fue analizado del 10 de junio al 30 de septiembre, Chicle List del 14 de junio al 18 de septiembre (fecha en que pone fin a sus actividades) y Aztlan Net del 1 de junio al 21 de septiembre. 
hay que tomar cierta distancia crítica y evaluar las herramientas de análisis examinando el contenido de los mensajes y las discusiones disponibles hasta el momento.

\section{LA LITERACY Y LA PALABRA ESCRITA}

Los tres grupos de discusión bajo estudio se encuentran albergados en servidores de Estados Unidos, están formados casi exclusivamente por chicanos, su forma de comunicación es escrita y la mayoría en inglés (con poca presencia del español y muchos juegos de palabras en spanglish). Los temas de discusión son sobre literatura, arte, cultura y sociedad, en particular relacionados con la cultura chicana e hispana en Estados Unidos y con la cultura mexicana y latinoamericana del sur del río Bravo.

Estos grupos de discusión electrónicos son de tipo intelectual, tanto por las características socioprofesionales de sus miembros como por sus temas de interés, su especialización en los temas discutidos, la frecuentación de sus miembros a circuitos formales institucionalizados en sus profesiones (simposios, coloquios, seminarios, encuentros) así como en la importancia acordada a la interacción cara a cara y a la práctica de la escritura como medio de hacerse presente y reconocible en el grupo. Desde este punto de vista, se hace referencia tanto a comunidades de interés como a la práctica de una literacy reciente. Empleo el concepto literacy no sólo en el sentido que tiene un grupo social de leer y escribir en forma particular sino de hacerlo también con herramientas informáticas, de ponerlas a su servicio para transmitir sus inquietudes de grupo y debatir asuntos de su interés, por medio de la palabra escrita y "haciendo como si" se encontraran cara a cara (Paravel 1998).

Esta literacy es acompañada por la propensión de los grupos intelectuales a organizarse en redes sociales, con un apoyo logístico importante (ser miembros de universidades, escribir en medios impresos de influencia, ser figuras de referencia en medios artísticos e intelectuales, contar con el apoyo de fundaciones y acceso 
a fondos para investigación, etc.), sujetos a la demostración de habilidades profesionales constantes en un medio con fuerte competencia por las oportunidades de trabajo, todo acompañado de una fuerte informalidad en el trato personal.

En los grupos de discusión electrónicos y en las universidades estadunidenses, el uso de herramientas informáticas es muy promovido, en particular el correo electrónico. El e-mail es un medio que posee sus propias características sociales de escritura pues se encuentra a medio camino entre lo oral y lo escrito ( op. cit., 102). Podríamos decir que se trata de una forma de "hablar escrita" o de "escritura hablada", pues el uso del correo electrónico es considerado como una forma de expresión instrumental, donde hay pocas formas de cortesía o, en todo caso, poco elaboradas, muy sobrias ("gracias", "nos vemos", "chao"). Otra particularidad del uso instrumental del correo electrónico es la facilidad con que las personas aceptan los errores gramaticales: palabras mal escritas, ausencia de acentos, escribir sólo con mayúsculas, oraciones mal construidas. Es una forma de escritura muy propia del lenguaje hablado. Esta forma de expresión escrita es, con frecuencia, acompañada de lo que E. J. Hall ha denominado como contexto rico, donde hay poca información y mucho contexto que la envuelve haciéndola rica en significados (Hall 1990). El contexto rico está dado por el conocimiento recíproco que tienen los participantes entre sí, sea personal o culturalmente. Además, en el caso del correo electrónico, las personas que se comunican entre sí suelen responder por medio de una reply (respuesta) que reproduce la totalidad del mensaje al que se contesta junto al texto que se escribe como respuesta. Esta particularidad ayuda a contextualizar los mensajes, aun cuando hayan pasado varios días y se haya olvidado lo que se dijo inicialmente. El contexto también se ve enriquecido por la práctica de adjuntar archivos a los correos: fotos, gráficas, ligas a páginas Web, imágenes en movimiento, ilustraciones, etcétera.

Tomando en cuenta la literacy y la forma de expresión instrumental y coloquial del correo electrónico, podremos explicar 
mucho del universo simbólico en que viven los participantes de los grupos electrónicos bajo análisis.

\section{"TIENES UN NUEVO MENSAJE"}

Como ya he señalado, los tres newsgroups que analizamos son: Chicle List (Chicano literature discussion list), Aztlan Net (Latino arts and letters of North America) y mexican.american (soc.culture.mexican.american). Los dos primeros son accesibles desde la www, el tercero desde Usenet. Mientras que la www, o Web, es la parte más accesible, comercial y popular de Internet, Usenet es una red que funciona de forma altruista. Los tres grupos son gratuitos y de libre acceso, animados y alimentados por los propios usuarios. Sólo el grupo mexican.american carece de moderador, mientras que los otros dos sí lo tienen.

La vitalidad de los grupos de discusión es evidente debido a la gran cantidad de mensajes intercambiados. Durante los primeros tres meses observados produjeron casi cuatro mil mensajes en total entre los tres. Tal cantidad es impresionante, pero hay que tomarla con reservas pues se trata de mensajes acumulados, es decir, contabiliza tanto los mensajes originales, como los mensajes de respuesta y, en uno de los casos, los mensajes provenientes de otros grupos de discusión relacionados. En segundo lugar, la participación varia enormemente al interior de cada uno de los tres grupos. Mientras que Clicle List produjo 355 mensajes, Aztlan Net 942 y mexican.american 2,652. Esta notable diferencia entre el último y los otros dos grupos se debe a una práctica usual entre los participantes de grupos de discusión: el envío múltiple o multienvío. Éste consiste en el envío de una misma respuesta a más de un grupo al mismo tiempo, generalmente con temáticas cercanas. Entre usuarios individuales también existe esta práctica, llamada forward, que consiste en enviar un mismo correo a varias personas a la vez. En Usenet las respuestas provenientes de otros grupos con temáticas semejantes suelen ser contabilizadas en los archivos electrónicos de cada grupo, por lo que no es extra- 
ño que la cifra acumulada de mensajes en mexican.american sea de 2,442, aunque los mensajes producidos por el grupo sólo sean 210. Explicaremos esto con detalle más adelante.

Una manera de analizar las formas en que se discute en los newsgroups es diferenciando los mensajes originales de los mensajes de respuesta (Bensaude 1998). Los mensajes originales son aquellos que se han escrito por vez primera; en cambio los mensajes de respuesta son aquellos que contestan a esos mensajes originales o a otros mensajes de respuesta. Esta diferencia es importante; permite delimitar mejor los temas de discusión de cada grupo, sus debates, sus consensos y sus representaciones sobre la identidad chicana en Internet. En efecto, no todos los mensajes merecen respuestas; en cambio, otros suelen suscitar vivas polémicas.

Aunque los tres newsgroups se dirigen a un público chicano con educación universitaria e inquietudes intelectuales, cada uno de ellos es diferente a los otros dos. Chicle List y Aztlan Net se centran en el arte, la cultura y la literatura chicana, mientras que mexican.american es más misceláneo en temas y contenidos. La participación en cada grupo sólo es posible mediante inscripción gratuita. El Cuadro 1 muestra los mensajes producidos por cada grupo en cada uno de los meses considerado.

\section{CUADRO 1}

Mensajes PRODUCidos POR NEWSGROUP SEGÚN MES, 2001

\begin{tabular}{lccccc} 
& Junio & Julio & Agosto & Septiembre & Total \\
mexican.american & 85 & 51 & 34 & 40 & 210 \\
Chicle List & 45 & 132 & 102 & 76 & 355 \\
Aztlan Net & 257 & 265 & 228 & 192 & 942 \\
Total & 387 & 448 & 364 & 308 & 1,507 \\
\hline
\end{tabular}

Fuente: elaboración propia.

Otra diferencia entre los grupos electrónicos consiste en el volumen y tipo de mensajes disponibles en cada uno de ellos. En Aztlan Net se produjeron 942 mensajes en tres meses debido a que en él son frecuentes los debates. En Clicle List hay menos 
debates y más anuncios diversos, por lo que se produjeron 355 mensajes en total. Finalmente, en mexican.american se produjeron 942 mensajes debido a que reproduce con frecuencia artículos de prensa, anuncios de interés variados; es donde hay menos debates, aunque paradójicamente son más intensos y con mayor participación.

Aztlan Net fue fundado el 6 de marzo de 2000, sus miembros inscritos eran 154 el 5 de septiembre de 2001 y sus archivos están disponibles para consulta a condición de inscribirse en el grupo. ${ }^{6}$ Chicle List fue fundado en 1991 por Teresa Márquez, de la Universidad de Nuevo México en Alburquerque. El grupo dejó de existir el 18 de septiembre de $2001 \mathrm{y}$, por desgracia, al parecer no existen archivos del grupo. ${ }^{7} \mathrm{El}$ grupo mexican.american fue fundado el 17 de noviembre de 1997 por Anthony Tiscareno, de la Universidad de Standford. Aunque el grupo funciona por inscripción a Usenet, sus archivos pueden consultarse a través de la Web, por medio del buscador Google, servicio Google Groups.

La participación masiva que llega a producirse en mexican.american se debe a las prácticas del multienvío y a la proximidad temática de varios grupos de discusión. Esto explica que en el periodo señalado los mensajes originales que por sí solo generó el grupo, fueran 210, mientras que al revisar los archivos del grupo encontramos que éstos se elevan a más de 2,600. Grupos próximos a las preocupaciones chicanas son: soc.culture.latinamerica (grupo de discusión sobre cultura y sociedad en América Latina), soc.culture.mexican (temas relacionados con México), soc.culture.puerto-rico (sobre Puerto Rico), alt.california (grupo sobre temas de California), alt.politics.inmigration (sobre políticas de migración) y alt.non.racism (sobre racismo).

${ }^{6}$ http://groups.yahoo.com/group/AztlanNet.

${ }^{7}$ Según nos lo hizo saber Teresa Hernández, ex moderadora del grupo, en un correo dirigido al autor de este trabajo el 27 de marzo 2002. 


\section{TIPOS DE MENSAJES Y COLEGIOS INVISIBLES}

El importante volumen de mensajes que circulan a través de los foros y listas de discusión, rebasa el aspecto cuantitativo pues se trata de información textual, por lo que su análisis debe preservar la particularidad de la palabra: la producción de significados, la dinámica de las discusiones y la toma de posiciones en la interpretación del universo simbólico de las comunidades electrónicas chicanas bajo estudio.

¿En estas comunidades de discusión electrónicas hay temas de referencia, es decir discursos y problemas que dominan? ¿Qué temas han suscitado mayor número de mensajes de respuesta y debate? ¿En torno a qué temas se crean mayores acuerdos y disensos?

La participación de los integrantes de cada grupo varía en función de los temas tratados a lo largo del tiempo. Encontramos a los miembros activos, en el caso de aquellos que participan de forma frecuente, y a los miembros pasivos, en el caso de los "observadores" que se contentan con leer los artículos sin intervenir en las discusiones. En la práctica hay alternancia entre roles activos y pasivos, sin embargo, es fácil distinguir un núcleo duro, otro de participantes ocasionales y otro más amplio y difuso de observadores.

Es fácil constatar la diversidad de temas en cada grupo, más difícil ha sido clasificarlos por temas. Inicialmente le hemos dado mayor seguimiento a los mensajes que más respuestas y opiniones han recibido de los otros participantes. Cuando un mensaje da lugar a respuestas acaloradas y encontradas se produce un debate. Los debates son interesantes de observar pues nos permiten ver las tomas de posiciones, formas de argumentar, la evolución de puntos de vista y luchas simbólicas por la apropiación y el reconocimiento del capital cultural por parte de los miembros de cada grupo. Los debates son formas discursivas que se aprenden, se demuestran y ponen en juego el capital cultural del grupo social.

Llamo dinámica de discusión a la manera como se van presentando las discusiones al interior de cada foro, a la creación de 
consensos y disensos, a la formación de opiniones y tomas de posición, a lo negociable y lo prohibido ("lo que no se dice"). ¿Cómo se lleva a cabo la literacy en los foros de discusión formados por chicanos intelectualizados?

Una buena manera de analizar las dinámicas de discusión en los grupos electrónicos es por medio de los temas debatidos. Al clasificar los mensajes por temas, aparecen dos grandes tipos de mensajes que desempeñan papeles diferentes. Por una parte, están los mensajes originales, y por otra, los mensajes huérfanos. Los mensajes originales son aquellos que aparecen por vez primera y que desatan mensajes de respuesta, mientras que los mensajes huérfanos no suscitan respuesta alguna. Los encabezados o títulos que acompañan cada mensaje permiten observar los mensajes que han suscitado respuesta, aunque no siempre esto es evidente, por lo que el análisis del contenido textual es indispensable.

En principio definiremos las discusiones generadas en los foros electrónicos como las respuestas asociadas al encabezado que aparece en la zona subject (asunto) de cada mensaje, que generalmente van acompañadas del prefijo “RE:". En estas respuestas se suele reproducir dentro del cuerpo del texto todo o parte del mensaje al que se responde. Las respuestas no necesariamente desatan debates. Para facilitar el estudio de los newsgroups distingo tres tipos de mensajes: los anuncios, las preguntas y las tomas de posición.

Los anuncios son temas nuevos a los que apenas se reacciona en el foro, generalmente se trata de mensajes que ofrecen información de interés general. He identificado siete tipos de anuncios que ilustro con ejemplos: ofertas de empleo ("Academic Skill Specialist English-Writing"), ${ }^{8}$ ofertas de productos o servicios (“Calaca Press Summer 2001 Calacatalog"), ${ }^{9}$ anuncios de conferencias o simposios ("Call for Papers III Congreso Internacional de literatura Chicana 22-24 de mayo de 2002", "Latina/Latino Writer's Forum") ${ }^{10}$ peticiones de artículos ("Paper-Work National

\footnotetext{
${ }^{8}$ Chicle List: 7 de agosto 2001.

${ }^{9}$ Chicle List: 31 de agosto 2001.

${ }^{10}$ Chicle List: 7 de septiembre 2001 y Aztlan Net: 30 de junio 2001, respectivamente.
} 
Hispanic Cultural Center-Alburquerque, NM"), ${ }^{11} \mathrm{FAQ},{ }^{12}$ anuncios diversos especializados ("Zopilote News. Electronic cultural/ literary Newsletter", "A few Chicano bookstores"13 y, por último, los anuncios parásitos, como el spamming (correo comercial no solicitado) y las cadenas de cartas. Los anuncios se presentan de manera continua y suelen estar ligados a la temática del foro.

Las preguntas son mensajes donde el autor espera obtener alguna respuesta por parte del grupo. Las respuestas pueden llegar incluso varios días después de formulada la pregunta. En las respuestas es frecuente la reproducción parcial o integral del mensaje al que se responde. Al responder a las preguntas los miembros del grupo esperan rendir servicio a la comunidad o bien demostrar sus competencias en el tema tratado. Veamos un ejemplo de pregunta:

From: T.T.C.

Subject: Films Set In Mexico And/Or Central America

Newsgroups: soc.culture.mexican.american

I am compiling a comprehensive list of films set in

Mexico and/or Central America.

In chronological order, so far, I have:

(...)

Further suggestions will be greatly appreciated..$^{14}$

En las tomas de posición se inscriben los temas en torno a los cuales su autor espera desatar un debate dentro de la comunidad electrónica. En los tres foros electrónicos bajo estudio las tomas de posición son frecuentes, lo cual no es raro tomando en cuenta su objetivo principal: la discusión de la identidad chicana, su literatura y sus problemas sociales. Un ejemplo de toma de posición que no desata polémica, aunque sí respuestas, es el siguiente:

${ }^{11}$ Chicle List: 5 de julio 2001

12 FAQ (Frequently Asked Questions), preguntas frecuentes en el lenguaje informático.

${ }^{13}$ Aztlan Net: 5 de julio 2001 y Aztlan Net: 13 de julio 2001, respectivamente.

${ }^{14}$ soc.culture.mexican.american: 16 de junio 2001. El autor del mensaje obtuvo 21 respuestas entre el 16 de junio y el 6 de julio. 
From: L.G.

Subject: Top ten sexy Latinas

I was surfing today and came across quesuave.net which listed

Catherine Zeta-Jones as one of the top ten sexy Latinas. Am I missing something? Or are they

pendejos who thought she was Latina because

she played one in Zorro ${ }^{15}$

Entre las respuestas que obtuvo el mensaje anterior destacan las siguientes por su ironía:

From: J.M.U.

Subject: Re: Top ten sexy Latinas

L. G. wrote:

$>$ Or are they pendejos who thought she was Latina because

$>$ she played one in Zorro?

The later :-)

BTW, the definition of «Latino/a» (oh, how I hate that «o/a,» maybe I should type «@»?»:-) is being taken over by the media and has turned into the new «Spanish» (remember when anyone who spoke Spanish was

«Spanish?»)...

Duck!!!

From: D. O. G.

Subject: Re: Top ten sexy Latinas

Yeah I remember. You were Spanish because it sounded nicer than Mexican.

From: L. G.

Subject: Re: Top ten sexy Latinas

Yeah, it sounds so much nicer than «greasy Mexican.» ;-p

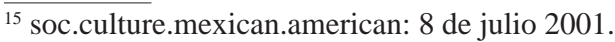


Del ejemplo anterior destacan algunas características frecuentes en los foros chicanos. En primer lugar está el uso de palabras o expresiones en español y en spanglish. Los chicanos usan mucho este recurso, al igual que el resto de los latinos que viven en Estados Unidos, como forma de distinción y diferenciación social frente al anglosajón. Hay un uso irónico en muchos mensajes; entre las formas que cubre esta ironía destacamos el uso de insultos, muchos de ellos expropiados a los propios anglosajones como forma de desactivación del insulto original para conferirle un nuevo sentido. Otra característica es el uso de smaleys, es decir, de caracteres escritos que transmiten emociones o estados de ánimo, de forma que el smaley ";-p" significa: "estoy bromeando" (es un guiño de ojo y una sonrisa vista de lado).

A partir de la lectura de los encabezados de los mensajes y de sus respuestas, del contenido de cada uno de ellos, de las firmas, de las invitaciones, de los lugares de encuentro, de las instituciones de apoyo y de los tipos de trabajo ejercidos aparece no sólo una cierta unidad temática en los asuntos tratados, sino también en la forma en que son tratados junto a las características socioprofesionales e intelectuales de los participantes. Dada esta semejanza, destaco la formación de colegios invisibles chicanos. Utilizo la idea de colegios invisibles en un sentido más amplio al empleado originalmente por D. J. de Solla Price cuando habla de las comunidades científicas y su frecuentación a redes sociales establecidas por los académicos y los investigadores como marcos principales de intercambio y competencia. ${ }^{16}$ En efecto, los grupos de discusión electrónicos chicanos funcionan como redes sociales abiertas, dinámicas y cambiantes que permiten la frecuentación de otros colegas, el intercambio de puntos de vista, donde se establecen formas de competencia informal entre ellos, realizan ajustes simbólicos de cuentas, son espacios de intercambio de informaciones y confrontación de conocimientos y es donde se

${ }_{16}$ Price Derek De Solla, Little science, big science, New York, Columbia university Press, 1963; Diana Crane, Invisible colleges: Diffusion of knowledge in scientific communities, Chicago, The University of Chicago Press, 1972, citados por Paravel (1998: 123). 
forman corrientes de opinión y formas de ver e interpretar el entorno social que conocen cierta forma de institucionalización. Es decir, mediante los mensajes intercambiados en los grupos de discusión chicanos se distinguen las formas en que sus integrantes debaten en torno a elementos distintivos de su identidad como mexicoamericanos y como intelectuales, cooperan y se confrontan entre sí, se distinguen y reconocen unos de otros mediante luchas por el capital simbólico cultural y social, se hacen visibles, acceden al reconocimiento social de sus pares por sus competencias y se les ofrecen oportunidades de promoción profesional.

Como se verá en el apartado siguiente, buena parte de los temas discutidos en las comunidades electrónicas chicanas giran en torno a la identidad y a la memoria colectiva del grupo.

\section{IDENTIDAD Y MEMORIA COLECTIVA: "Mi CASA (NO) ES SU CASA"}

¿Qué temas son específicos de los foros electrónicos chicanos? ¿En torno a qué discuten e intercambian opiniones e informaciones? Hay un abanico de temas y asuntos de interés que les son específicos relacionados con su herencia cultural y sus intereses profesionales. Algunos de ellos son los siguientes:

a) Mensajes y temáticas en torno a la herencia e identidad cultural del grupo: "Sleeping Mexican image"17 (debate sobre el origen del estereotipo del mexicano dormido bajo un gran sombrero y recargado en un nopal), "Help hended: Documenting World War I Participation"18 (donde se pide ayuda para documentar e investigar la participación de chicanos en la Primera Guerra Mundial, un tema menos conocido que su participación en la Segunda Guerra Mundial, la Guerra de Vietnam u otras más recientes).

b) Mensajes institucionales de las diferentes profesiones de los miembros de los colegios invisibles chicanos (seminarios, coloquios, publicaciones, etcétera).

\footnotetext{
${ }^{17}$ Chicle List: junio de 2001.

${ }^{18}$ Chicle List: 28 de agosto de 2001.
} 
c) El uso de un campo lexical propio al grupo (uso del spanglish y temas relacionados con México).

d) Manifestaciones de solidaridad con otros grupos ("Ecumenical Effort for Vieques"19 (Vieques es una pequeña isla de Puerto Rico usada como campo de tiro de la armada estadunidense), "Chiapas crisis confronted"20 (información sobre el movimiento zapatista en Chiapas).

e) Avisos y debates sobre eventos culturales de interés ("Celebrate Espresso Mi Cultura's 3rd anniversary", ${ }^{21}$ "Post-Chicano Art in Reforma", ${ }^{22}$ "Second Latin Grammys Celebrate Latino Roots..." ${ }^{23}$ (Discusión sobre si los premios Grammy, de la industria musical de EU, son o no un reconocimiento a las raíces culturales latinas. La premiación debía llevarse a cabo en la ciudad de Los Ángeles el 11 de septiembre, día de los atentados terroristas. La ceremonia fue aplazada de forma indefinida, la discusión en el foro electrónico también).

f) Debates en torno a las letras chicanas y latinas ("Chicano detective favor"; 24 "Voices from the Barrio"). ${ }^{25}$

g) Intercambio de herramientas de comunicación (direcciones electrónicas de revistas, artículos de prensa, de sitios web, etc.) y anuncios varios (perfiles solicitados en ofertas de empleo o ayuda solicitada por estudiantes de posgrado). ${ }^{26}$

En los grupos de discusión los debates suelen desarrollarse a lo largo de varios días, en ocasiones en torno a la definición de un solo término, dejando poco espacio a otras intervenciones. Como ejemplo tenemos el debate sucedido en Aztlan Net en torno a la población de sangre negra en México ("Bloods in Mexico"). ${ }^{27} \mathrm{El}$

${ }^{19}$ Chicle List: 5 de julio de 2001.

${ }^{20}$ soc.culture.mexican.american: 21 de junio de 2001 .

${ }^{21}$ Aztlan Net: 5 de agosto de 2001.

${ }^{22}$ Aztlan Net: 7 de agosto de 2001.

${ }^{23}$ Aztlan Net: 10 de septiembre de 2001.

${ }^{24}$ Chicle List: 8 de septiembre de 2001.

${ }^{25}$ Aztlan Net: 10 de julio de 2001.

26 "Chicano Teachers Needed in Chicago..." (Chicle List: 4 de septiembre 2001), "Swedish graduate student studying Chicano English" (Aztlan Net: 14 de septiembre 2001).

${ }^{27}$ Aztlan Net: 12-14 de julio de 2001. 
debate fue intenso durante tres días, ocupando casi todas las intervenciones, aunque después siguieron apareciendo otras respuestas en forma aislada. Las intervenciones iban desde datos y precisiones censales hasta referencias bibliográficas, pasando por debates históricos, anécdotas personales, comentarios sarcásticos y el envío de artículos. Cada respuesta en el debate es de diferente nivel y están más allá de la búsqueda de un consenso, hay tomas de posición en las que cada participante desea hacerse oír, demostrar sus conocimientos, realizar ajustes de cuentas, interpretar o reflexionar sobre su mundo inmediato. También ocurre que los debates evolucionan y se transforman. El mismo ejemplo de "Bloods in Mexico" se transformó en una discusión sobre el papel ejercido por la extrema derecha en México durante la Segunda Guerra Mundial, sus vínculos con otros grupos conservadores mexicanos y sus relaciones con el partido Nazi alemán. La nueva discusión también cambió de título para subrayar su nuevo giro; ahora se llamaba "Nazis in México (was Re: Bloods in Mexico)". A partir de ahí la discusión se concentró en la precisión de fuentes bibliográficas, cambio que también reflejó su nuevo título: “El retorno de los brujos (was: Nazis in Mexico was Re: Bloods in Mexico)". ${ }^{28}$

El debate anterior es ilustrativo de lo que sucede en los grupos de discusión. Se trata de tomas de posición donde cada actor busca hacerse "visible" mediante la demostración de sus competencias o de su capital cultural. Dicha visibilidad es clara al constatar que cada contribución va firmada por su autor. Algunos firman sus contribuciones con su nombre, puesto y profesión. Firmar las contribuciones propias no sólo representa la búsqueda de reconocimiento de los demás, sino también la formación de redes sociales de trabajo y amistad. En ocasiones los mensajes van firmados por alguna asociación o institución, como en el caso de las ofertas de trabajo, las convocatorias a coloquios y las invitaciones a festivales culturales. La diversidad de tipos de mensajes que circulan en los foros electrónicos permite adelantar la idea de que los foros

$\overline{{ }^{28} 17-19 \text { de julio de } 2001 .}$ 
no sólo funcionan como ágoras, sino también como lugares de visibilidad individual y colectiva, de uno mismo hacia los demás, y del grupo hacia otros colectivos. Otra pista de esta visibilidad y diversidad de mensajes que circulan entre los foros electrónicos está en relación con las facilidades técnicas que ofrece Internet: envío de documentos adjuntos (attachments) para difundir artículos, imágenes, convocatorias, paginas Web, ligas a otros sitios, etc., complementados con el uso del correo electrónico, el multienvío, o los chats (salones de conversación) que permiten el encuentro simultáneo con otros participantes. El grupo Aztlan Net mantuvo durante varios meses un chat semanal disponible para sus miembros: los "Tuesday Night at Aztlan Net", que ya desapareció.

Por tratarse de un grupo social con una fuerte herencia cultural anclada en México, los chicanos suelen preocuparse por los acontecimientos y eventos relacionados con su tierra de origen, $o$ bien discuten las interrelaciones entre la cultura mexicana y la estadunidense, o las vicisitudes de los chicanos en Estados Unidos. Al tratarse de grupos intelectualizados, muchos de ellos investigadores universitarios, los chicanos de los grupos electrónicos no sólo discuten y cuestionan las versiones oficiales de las historias chicana, mexicana y estadunidense, también la investigan y participan en forma activa en su constitución como grupo étnico con una fuerte presencia en la sociedad estadunidense: solicitan información sobre la participación de los chicanos en la Primera y en la Segunda Guerra Mundial junto al ejército de EU, se cuestionan sobre el significado del 5 de Mayo en Estados Unidos, comparan el Día de Muertos y Halloween, analizan la mitología azteca, discuten sobre las exposiciones de carteles históricos del movimiento chicano de los años setenta, debaten alguna nueva biografía publicada en Estados Unidos sobre la vida de Sor Juana Inés de la Cruz, se avisan entre sí de la emisión de timbres postales con el rostro de Frida Kalho por parte del correo estadunidense, participan en la restauración de los murales chicanos en Los Ángeles o San Diego, hacen circular información sobre los desfiles de Low 
Riders, etc. Es decir, mantienen un diálogo permanente acerca de las fuentes que configuran el conjunto de su identidad y su memoria colectiva como chicanos.

Pero no sólo discuten de fechas y eventos relacionados con su vida como grupo social que alimentan su memoria colectiva, también lo hacen por medio de sus disposiciones hechas cuerpo, en particular mediante el uso de expresiones idiomáticas en español, que se encuentra en relación con la forma en que expresan su literacy.

En principio la literacy electrónica aparece en la forma como se argumenta y, sobre todo, se contrargumenta. Por ejemplo, seleccionando párrafos del mensaje al que se responde para en seguida rebatirlo o hacerle alguna observación. En los grupos electrónicos esto es visible porque los mensajes reproducidos suelen aparecer de diferente color y con el signo electrónico ">" antes de cada renglón.

Como ejemplo, en el mensaje llamado "Texas Americans: Were You forced to Talk English?", la autora se pregunta acerca de la conveniencia de permitir la entrada de más mexicanos en las escuelas de educación pública de Estados Unidos, pues en el colegio de su hijo es obligatorio aprender español y leer algunas obras literarias chicanas, entre ellas La casa de Mango Street, de Sandra Cisneros, considerada una de las obras modernas más importantes de la literatura chicana. En una de las respuestas que suscitó dicho mensaje vemos cómo se toman partes seleccionadas del mensaje original para hacer observaciones y criticar su postura chovinista:

$>$ importantly I say to the teacher who takes

> «The house on Mango Street» over «Lord of the Flies», or «The Pearl» is

$>$ doing more of an injustice to their students.

Why? Why is «The Pearl» better then «The House on Mango Street?» 
$>$ The commonality we have as a nation is our culture, our culture is what

A culture that is in reality a mish-mash of many. Or do you think that the gringos, all solitos, came up with cattle wrangling??

Como se observa, la autora del mensaje original dice que es una injusticia leer ese libro antes que, por ejemplo, El señor de las moscas o La perla. En la respuesta no sólo se han seleccionado párrafos del mensaje original, sino que también se recurre a palabras en español.

Entre las disposiciones hechas cuerpo que distinguen a los chicanos, está el uso del español y del spanglish, que cuando se emplean tienen un fuerte valor simbólico. Para Ada Savin (1998) el español y el spanglish desempeñan un papel importante en la definición de la identidad colectiva de los chicanos, a la vez como medio y como fin, como proceso y como resultado. Aunque el idioma predominante sea el inglés, la utilización de palabras en español o spanglish tiene por fin reafirmar la diferencia como resultado de una estrategia lingüística, muchas veces inconsciente, otras de forma consciente. Donde mejor se observa el uso del español no es en las argumentaciones, sino en los insultos y las descalificaciones:

From: J.

Subject: Re: Aztlan does NOT exist ${ }^{30}$

[respondiendo a P.P.S.]

If you are such a hater of

Mexicoaméicanos then why are you in that ng [newsgroup]?

Yo pienso que tienes una mente como un perro, no?

[P.P.S. responde a J.]

From: P.P.S.

${ }^{29} 20$ de junio de 2001.

${ }^{30}$ soc.culture.mexican.american: 17 de junio de 2001. La polémica tuvo lugar del 8 al 17 de junio de 2001. 
Subject: Re: Aztlan does NoT exist

$>$ If you are such a hater of Mexicoaméicanos then why are you in that ng?

$>$ Yo pienso que tienes una mente como un perro, no?

quizá, sino por lo menos yo no parezca un perro.

Stupid BEANER!

Aquí vemos cómo ambos participantes, cuyo mensaje original dio origen a 34 respuestas en nueve días, se insultan mutuamente. Los insultos y las descalificaciones en español por parte de los chicanos son muestra del valor simbólico que le confieren al idioma, de forma consciente o no, como estrategia de distinción frente al anglo.

En estos grupos de discusión electrónicos las polémicas suelen desatarse cuando se tocan temas sensibles a las diferentes comunidades étnicas de Estados Unidos. En efecto, uno de los principales atractivos de los newsgroups reside en su capacidad de generar debates sobre temas excluidos de otras áreas de la vida cotidiana. Frente a lo "políticamente correcto" los grupos de discusión se permiten debatir, con toda clase de tonos y maneras, temas candentes relacionados con el racismo, como los matrimonios entre miembros de diferentes etnias, ${ }^{31}$ o preguntarse sobre la supuesta superioridad en ciertos aspectos de los asiáticos frente a los hispanos. ${ }^{32}$ Los dos ejemplos anteriores nos permiten ver cómo temas considerados tabúes en otras áreas de la vida social estadunidense normal son debatidos con toda libertad en los grupos de discusión. De la misma manera, ambos ejemplos nos sirven para ilustrar las prácticas de multienvío practicados en ciertos foros de Usenet.

Como ya ha sido señalado, el grupo soc.culture.mexican.american forma parte de la red Usenet, donde existen grupos electrónicos prácti-

31 "I Wouldn't Want to Marry One", soc.culture.mexican.american, 21 de junio de 2001.

32 "Hispanics = Asians whitout a master plan", soc.culture.mexican.american, 20 de julio de 2001. 
camente para todos los gustos y temas y donde no es extraño encontrar un uso frecuente de la práctica de multienvío. En los dos ejemplos mencionados en el párrafo anterior, la práctica del multienvío alimenta en forma espectacular la cantidad de mensajes producidos en torno a ciertos temas. Por ejemplo, el mensaje sobre los matrimonios entre miembros de diferentes etnias generó 200 mensajes en tan sólo tres días. Esta inflación se explica en parte por el tema y por ser mensajes generados en cinco newsgroups a la vez. ${ }^{33}$ Lo mismo se puede decir del segundo mensaje, relacionado con la relativa superioridad de los asiáticos frente a los hispanos, ${ }^{34}$ que generó 44 respuestas. Ambos debates se originaron cuando el autor del mensaje original comentaba un artículo aparecido en la prensa de eu y pedía a los miembros de diferentes grupos su opinión.

El que algunos temas sean discutidos de forma simultánea en dos o más grupos nos permite ver la multiparticipación de algunos usuarios en más de un grupo a la vez. Esta multiparticipación muestra cómo ciertos temas son desplazados hacia otros grupos, al tiempo que confirman la importancia de las redes sociales tejidas y mantenidas por los propios usuarios a través de los grupos de discusión. En el caso de los grupos chicanos de los foros bajo análisis, como minoría étnica ilustrada, nos preguntamos acerca del alcance y las modalidades de sus debates en su entorno "real". Estas reflexiones sólo podremos fundamentarlas mejor a medida que avancemos en el trabajo de investigación.

El uso de palabras y frases en español, el debate de la identidad colectiva e individual, la solidaridad con otros grupos chicanos, hispanos o latinoamericanos, y los debates sobre sus diferencias con otros grupos étnicos de Estados Unidos en los grupos de discusión chicanos forman en conjunto una reivindicación de su alteridad cultural, étnica e histórica, cada una de ellas no exenta de una dimensión política, al menos simbólica.

\footnotetext{
${ }^{33}$ soc.culture.african.american, soc.culture.mexican.american, soc.culture.asian.american, soc.culture.jewish y alt.native. Polémica del 21 al 23 de julio.

${ }^{34}$ soc.culture.asian.american, soc.culture.mexican.american, soc.culture.usa, alt.california, soc.culture.brazil, soc.culture.taiwan, debate del 30 de julio al 4 de agosto.
} 
Dentro de las críticas que formulo a los grupos de discusión, y no sólo a los chicanos, mexicoamericanos o latinos, se encuentra cierto "exceso" de información producida. Hay un peligro de saturación ante la gran cantidad de mensajes en circulación. Parece que todos, muchos, desean hacerse oír; el peligro es que nadie termine escuchando. Las siguientes preguntas ilustrarían esta situación: ¿Cuántos de ellos leen todos los mensajes que, por momentos, llegan a saturar las cuentas de correo? En ese caso, cómo opera la selectividad para leer ciertos mensajes e ignorar el resto? Por otra parte, es frecuente la transmisión de rumores sobre virus y leyendas urbanas, así como la reproducción de estereotipos culturales en algunas discusiones. Uno de los peligros evidentes de Internet, y su velocidad de transmisión, es la facilidad con que se propagan informaciones no verificadas o insuficientemente razonadas.

Si la cultura y la identidad, al ser dinámicas, son una serie de símbolos y abstracciones, creencias y valores que funcionan como una estrategia colectiva mediante las cuales se organizan y se hacen comprensibles la experiencia individual y colectiva, entonces ¿cómo se construye, dentro del paisaje audiovisual de las nuevas tecnologías de la comunicación, la asimilación alternativa, y qué lugar tienen en ella la memoria colectiva y la representación de la identidad individual y colectiva?

Los mensajes producidos dentro de los grupos de discusión chicanos así como sus temas de conversación y debate, se inscriben dentro del proceso de reflexibilidad del que habla Anthony Giddens (1996), es decir, el proceso de pensarse a sí mismos que contribuye a la construcción de la identidad y de la historia, individual y colectiva, de los individuos y grupos sociales en la modernidad.

\section{Conclusiones}

Me parece pertinente equiparar las comunidades electrónicas examinadas con los colegios invisibles, en la medida en que permiten la creación y frecuentación de redes sociales informales como 
marcos principales de intercambio y competencia. Desde este punto de vista, son los grupos sociales quienes imponen su lógica de funcionamiento a las herramientas tecnológicas para crear y alimentar su universo cotidiano y sus preocupaciones diarias.

Un primer y somero análisis del contenido de los mensajes intercambiados en los tres grupos de discusión electrónicos confirma la importancia de la dimensión "relacional" de los intercambios, es decir, la función principal de los foros electrónicos es la construcción y el mantenimiento de las relaciones sociales mediante el intercambio y discusión de ideas que ayudan a reflexionar en el lugar ocupado por cada grupo dentro de un contexto étnico más amplio, como es la sociedad estadunidense.

Al mismo tiempo, cada uno de los grupos electrónicos es diferente de los otros dos. El grupo soc.culture.mexican.american es el más diversificado en sus temas, tiene más mensajes de carácter general y conoce menos polémicas, aunque más virulentas cuando las hay. Aztlan Net produce más mensajes originales, tiene menos anuncios, hay un núcleo duro de participantes y las polémicas son más frecuentes. Finalmente, Chicle List reproduce más anuncios y artículos de carácter general, se centra más en la literatura que los otros dos grupos y presenta debates menos frecuentes que en Aztlan Net, pero más numerosos que en soc.culture.mexican.american.

Los foros electrónicos son lugares de discusión colectivos, de creación de nuevas relaciones y constituyen un lugar privilegiado de observación de las prácticas de intercambio donde se desarrollan debates en torno a la identidad de la minoría chicana, de su arte y de su literatura. De ahí que no sólo asistamos a una puesta en escena de la visibilidad de una comunidad electrónica, sino también a la puesta en práctica de sus formas discursivas y de sus reivindicaciones de manera "visible" por medio de su escritura y de sus autores.

Las intervenciones en los newsgroups están lejos de ser meros intercambios de savoir-faire eruditos por parte de los participantes. El aspecto tecnológico ofrecido por Internet, al permitir el 
intercambio de ligas y documentos adjuntos, tiene una amplia e importante repercusión social, pues vuelve accesibles informaciones interesantes a los miembros de una comunidad de interés al reenviarlos a diferentes paginas Web, imágenes adjuntas o informaciones diversas. Además, muestra que las ligas Web, los foros electrónicos y el correo electrónico se encuentran en estrecha relación como instrumentos de comunicación y de mantenimiento de las relaciones sociales, al mismo tiempo que modifican la circulación del saber, alientan la organización descentralizada y animan de forma discursiva (por medio de la palabra escrita) los debates de la identidad en las comunidades electrónicas.

Mientras que el correo electrónico es una forma de relación de punto a punto, de persona a persona, los grupos de discusión electrónicos son una forma de comunicación de una persona hacia varias. Sus comunicaciones permiten ver los círculos concéntricos de las identidades colectivas donde cada participante se siente en relación, como miembro y como actor. Algunos "toman la palabra" en forma constante, la mayoría en forma esporádica, y otros se limitan a observar. En estos intercambios se adivinan amistades y lazos fuertes; en otros son patentes las enemistades y los ajustes de cuentas. En la medida en que grupos como Chicle List y Aztlan Net se especializan en la literatura y en las artes chicanas, los debates continuos que en ellos se desarrollan convierten a ambos foros como en una especie de coloquios permanentes, mientras que el grupo soc.culture.mexican.american se asemeja más a un tablero de anuncios en los que los participantes dejan "copias" de artículos a los interesados. En tanto que los dos primeros son una fuente permanente de debates, el tercero lo es de productos. De ahí que no se deba soslayar el impacto que tiene la comunicación mediada por la computadora en los grupos de discusión electrónicos chicanos u de otro tipo. Los mensajes generados en ellos se sitúan entre la comunicación escrita y la comunicación oral, tanto por su estilo como por su sabor. Es en este punto donde se reflejan las características de las discusiones que antes se celebraban en los cafés y en los salones literarios: en 
el intercambio de conocimientos y la circulación de novedades y "chismes" que interesan a cada grupo.

El tema de la identidad chicana debatida en los grupos de discusión electrónicos es esencial, pero se trata ahora de una reivindicación que no se opone necesariamente al anglosajón, como en los años setenta, al inicio de El Movimiento Chicano. Ahora se trata más bien de un discurso de apertura, pues la afirmación de la identidad chicana de hoy acepta y reconoce la alteridad, no sólo del anglo sino de otros grupos étnicos y sociales.

Aún hace falta avanzar en una discusión más propiamente etnológica en torno a los nuevos medios de comunicación electrónicos y su implicación en las formas de interacción que convocan y en las modalidades de gestión del conocimiento que suponen. Sólo el estudio de casos particulares podrá dar respuestas más detalladas. Por ahora los tres foros cibernéticos que observamos participan en la renovación, la actualización y la movilización de los intermediarios sociales implicados en la difusión, enseñanza e investigación de las letras, la cultura y la identidad chicanas.

De ahí mi interés por el estudio de los grupos electrónicos. En ellos es posible observar la lenta transformación de sus autorrepresentaciones, de sus puestas en escena por medio de la escritura y de los momentos de demostración de sus saberes movilizados.

La comunicación electrónica facilita el encuentro, la organización, el intercambio, el debate y la visibilidad de grupos sociales con intereses afines, más aun cuando se trata de comunidades con intereses culturales e intelectuales particulares. Aunque también pueden producir saturación ante el exceso de mensajes enviados y por la propagación de falsos rumores e informaciones no verificadas.

Por último, se ponen en juego estrategias particulares de acceso a la visibilidad mediante la palabra y la imagen (a través de la puesta en circulación de fotografías y paginas Web que son, a final de cuentas, "puestas en escena"). Ambas otorgan visibilidad 
en el mundo electrónico y en el mundo real: ocupando espacios, produciendo obras y textos, dando lugar a "hablar de sî" por los otros, llenando vacíos dejados por los medios de comunicación tradicionales, creando y fortaleciendo nuevos circuitos de comunicación y acción. Esto prueba que Internet, y sus herramientas, más que ser un "mundo aparte", "virtual”, es una extensión más del mundo real.

\section{REFERENCIAS BIBLIOGRÁFICAS}

BaIlly, Florence et al. (2002) Practiques professionnelles et usages des écrits électroniques. París: L'Harmattan.

Beaudoin, Valérie, y Julia Velkovska (1999) “Constitution d'un espace de communication sur Internet (forums, pages personnelles, courrier électronique)”, Réseaux, vol. 17, núm. 97, pp. 121-177.

Bensaude, Alain (1998) "Supervision des flux d'échanges d'informations dans les forums électroniques: Une approche sémiotique pour la catégorisation de phénomènes observables et mensurables dans les newsgroups", en Nicolas Guéguen y Laurence Tobin (eds.), Communication, société et Internet. París: L'Harmattan, pp. 87-104.

Breton, Philippe (2000) Le culte de l'Internet. Une menace pour le lien social? París: La Découverte.

Cavanagh, Allison (1999) "Behauvoir in public?: Ethics in online ethnography", Cybersociology, núm. 6 (http://www.socio.demon.co.uk/magazine/6/ cavanagh.html).

Dery, Mark (1998) Velocidad de escape. La cibercultura en el final del siglo. Madrid: Siruela.

Dupuy, Gabriel (2002) Internet. Géographie d'un réseau. París: Ellipses.

Dyson, Esther (2000) Release 2.0. Madrid: Ediciones B.

FLichy, Patrice (2001) L'Imaginaire d'Internet. París: La Découverte.

GArcía Canclini, Néstor (1999) La globalización imaginada. Buenos Aires/Barcelona/México: Paidós.

GidDEns, Anthony (1996) Modernidad e identidad del yo. La construcción de la identidad del yo en la modernidad tardía. Barcelona: Alianza.

Hall, Edward T. (1990) El lenguaje silencioso, Col. "Los Noventa", núm. 32. México: CNCA-Alianza Editorial Mexicana.

Maffesoli, Michel (2000) Le temps des tribus. Le déclin de l'individualisme dans les sociétés postmodernes. París: La Table Ronde.

MATtelart, Armand (2001) Histoire de la société de l'Information. París: Editions La Découverte. 
Negroponte, Nicholas (1996) Ser digital. México: Atlántida-Oceano.

PACCAGNELlA, Luciano (1997) "Getting the seats of your pants dirty: Strategies for ethnographic research on virtual communities", Journal of Computer Mediated Communication, vol. 3, núm. 1, junio (http:jcmc.huji.ac.il/vol3/ issue1/paccagnella.html).

PARAVEL, Véréna (1998) "Réseaux scientifiques et communication électronique: Étude des trois groupes de discussion”, en Nicolas Guéguen y Laurence Tobin (eds.), Communication, société et Internet. París: L'Harmattan, pp. 121-138.

PosTER, Mark (1998) “Cyberdemocracy: Internet and the public sphere”, en David Foster (editor), Internet culture. Nueva York: Routledge, pp. 201-217.

QuÉAu, Philippe (1995) Lo virtual. Virtudes y vértigos. Barcelona: Paidós.

Savin, Ada (1998) Les Chicanos aux Etats Unis. Etrangers dans leur propre pays? París: L'Harmattan.

Verville, Danielle, y Jean-Paul Lafrance (1999) “L'Art de bavarder sur Internet", Réseaux, vol. 17, núm. 97, pp. 179-209.

WeBb, Stephen (1999) “Cyberspace as everyday life”, Cybersociology, núm. 5. (http://sites.netscape.net/deleuzianrescal/ciberspaceverydaylife).

Wellman, Barry, y Milena Gulia (1999) "Virtual communities as communities. Net surfers don't ride alone”, en Marc A. Smith y Peter Kollock (eds.), Communities in Cyberspace. Londres/Nueva York: Routledge, pp. 167-194. Wolton, Dominique (1999) Internet et après? Une critique des nouveaux médias. París: Flammarion. 